\title{
La naturaleza del aprendizaje: Usando la investigación para inspirar la práctica
}

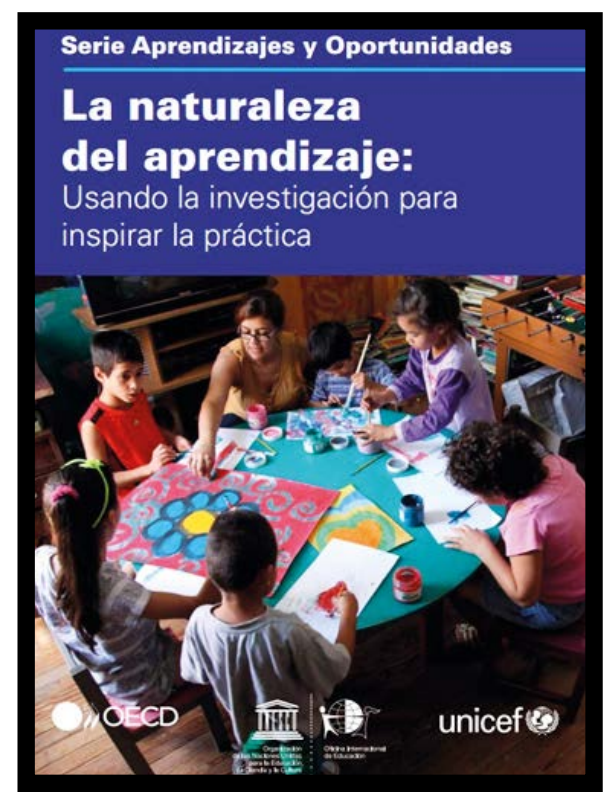

OCDE, OIE-UNESCO, UNICEF LACRO 2016. La naturaleza del aprendizaje: Usando la investigación para inspirar la práctica.

Esta publicación es una adaptación del documento originalmente publicado en inglés en el 2010 por la OCDE con el título The Nature of Learning: Using Research to Inspire Practice (editado por Hanna Dumont, David Istance y Francisco Benavides). Esta publicación incluye la traducción por la OIE-UNESCO y UNICEF LACRO de los capítulos 1, 2, 3, 4, 5, 6, 7, 9 y 11, un resumen ejecutivo, un resumen de cuatro capítulos que no fueron traducidos en su totalidad por no adecuarse específicamente a la realidad de América Latina y el Caribe, así como un nuevo capítulo sobre América Latina. La calidad de la traducción y su coherencia con el texto en lengua original son responsabilidad exclusiva del autor de la traducción. En caso de discrepancia entre la obra original y la traducción, sólo el texto de la obra original se considerará como válido. Las opiniones expresadas y los argumentos aquí expuestos no reflejan necesariamente los puntos de vista oficiales de los países miembros de la OCDE, de la UNESCO o de UNICEF.

Una de las claves para lograr la mejora sostenida de la calidad y la equidad en la educación, así como asentar las bases de una genuina inclusión en este sector, se basa en disponer de sólidos marcos de referencia conceptuales y de evidencia empírica robusta acerca de cómo potenciar y democratizar las oportunidades, los procesos y los resultados de aprendizaje. Así lo entienden la Organización para la Cooperación y el Desarrollo Económicos (OCDE), la Oficina Regional para América Latina y el Caribe de UNICEF (UNICEFLACRO) y la Oficina Internacional de Educación de la UNESCO (OIE-UNESCO) enfatizando que el logro de conocimiento relevante y sustentable implica conocer y entender en profundidad la diversidad de contextos, componentes y procesos implicados en todo aprendizaje y, a la vez, tener los conocimientos y las competencias institucionales y docentes requeridas para 
apoyar de manera personalizada el aprendizaje de cada estudiante en un ambiente colaborativo.

Bajo estas premisas, las tres instituciones acordaron unir esfuerzos y poner a disposición de la comunidad de educadores de América Latina y el Caribe el libro.

La naturaleza del aprendizaje: Usando la investigación para inspirar la práctica, versión en español del documento The Nature of Learning: Using Research to Inspire Practice, originalmente publicado por la OCDE en el 2010 y editado por Hanna Dumont, David Istance y Francisco Benavides. Esta publicación incluye investigación científica que ayuda a entender cómo las personas aprenden mejor y qué ambientes de aprendizaje facilitan este proceso.

Esta versión en español, recoge del documento original: (i) una selección de nueve capítulos que fueron traducidos en su totalidad debido a su pertinencia para América Latina y el Caribe; (ii) un resumen de cuatro capítulos que no fueron traducidos en su totalidad por no adecuarse específicamente a la realidad de América Latina y el Caribe. Finalmente se añade a esta versión (iii) un nuevo capítulo sobre América Latina preparado por la investigadora Inés Aguerrondo, enfocado en el análisis de los pobres resultados que logran los sistemas educativos en la región en relación con el aprendizaje. Se argumenta en torno a la necesidad de revisar las bases epistemológicas desde donde se diseña la función de distribución de conocimiento en la sociedad del tercer milenio y en particular en relación a uno de los nudos centrales de la educación, como son las propuestas curriculares y pedagógicas.

La OCDE concedió generosamente a UNICEF y a la OIE-UNESCO los derechos no exclusivos de traducir y publicar el documento original, mientras que UNICEF financió su traducción al español y la elaboración del capítulo sobre América Latina. La coordinación de la versión en español estuvo a cargo de la OIE-UNESCO en consulta con OCDE y UNICEF-LACRO.

Aspiramos a que en el marco de la Agenda Educativa 2030, esta publicación constituya una herramienta de trabajo de apoyo a los países en el logro de las metas planteadas en torno al Objetivo de Desarrollo Sustentable 4 (ODS 4) de "garantizar una educación inclusiva, equitativa y de calidad y promover oportunidades de aprendizaje durante toda la vida para todos". 